$(x, y)$

$3 x^{6}$

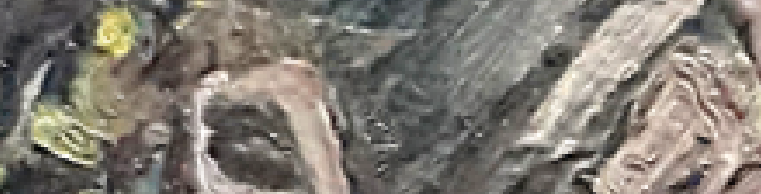

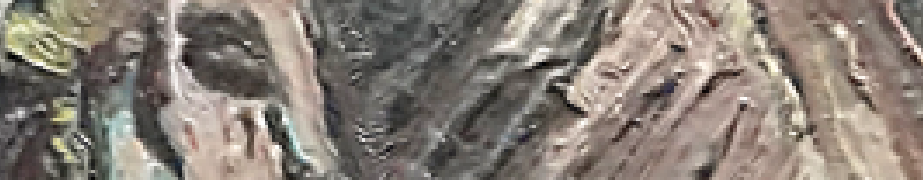

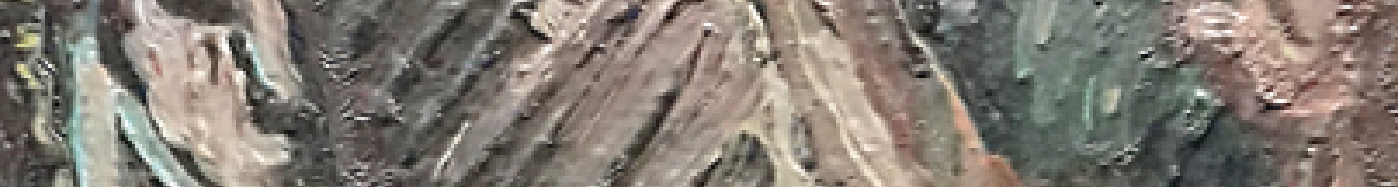

Ha 1 .

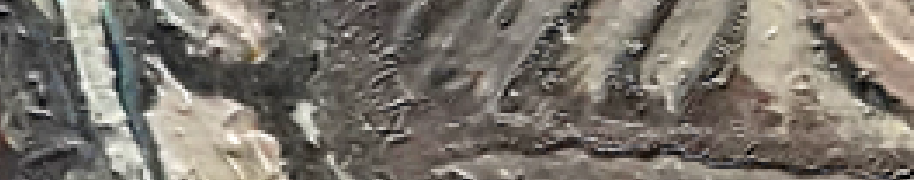

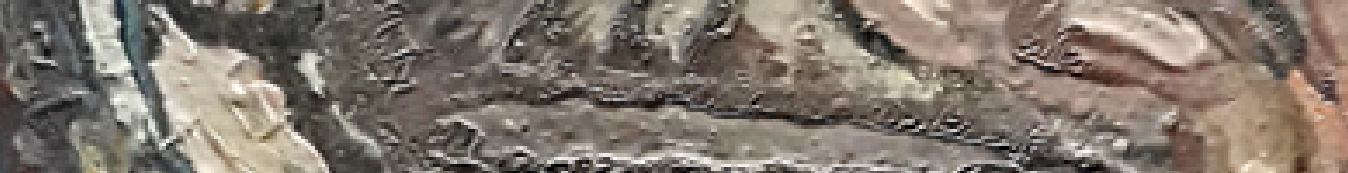

s

2805

का.

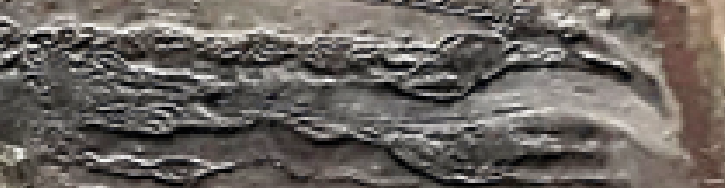

3 3.

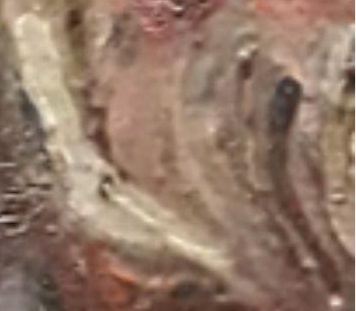

3.96
3

Se

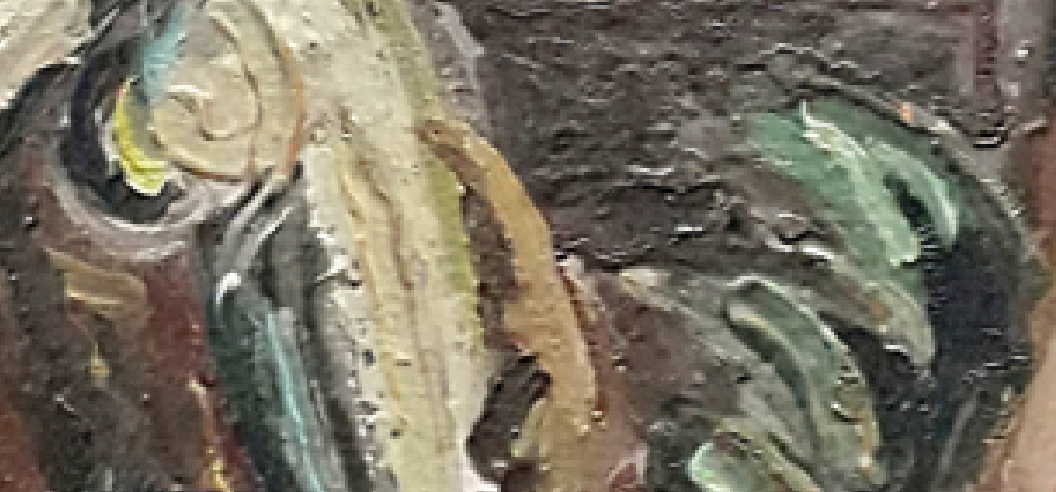

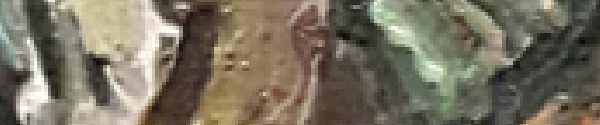

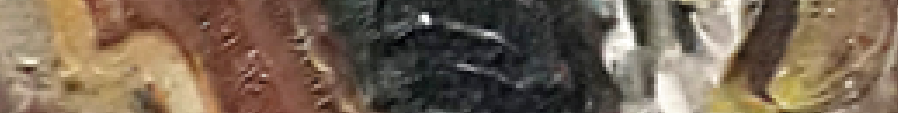

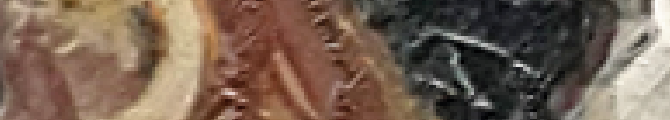

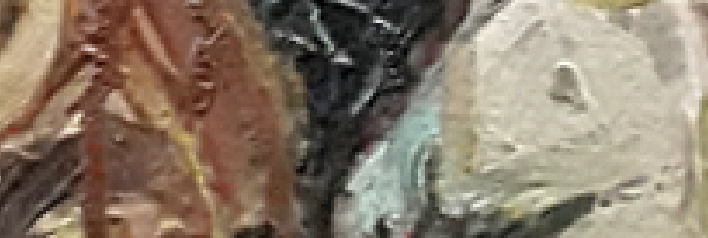

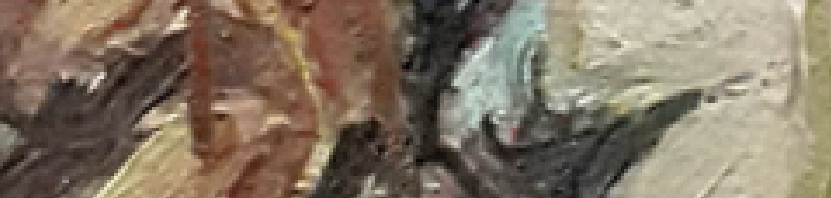




\title{
Expresionismo del Sur: hacia la definición de un arte propio
}

\author{
María Frick \\ Sistema Nacional de Investigación \\ mariafrick@gmail.com \\ Montevideo - Uruguay
}

\begin{abstract}
Resumen
Basados en el supuesto de que los artistas latinoamericanos participaron del movimiento expresionista internacional, se utiliza un enfoque de análisis formal para identificar los elementos plásticos que caracterizan a este cuerpo de obras en términos de la representación de los temas y su contenido expresivo. Para este propósito se ha considerado una serie de obras reconocidas, donde se aplica la categorización propuesta por Amalia Polleri, María Rovira y Brenda Lissardo (1993), como una primera aproximación necesaria, cuyas conclusiones -lejos de generar deducciones irrevocablespermitan bosquejar un campo de estudio que pueda ser abordado con mayor profundidad en futuras investigaciones.
\end{abstract}

Palabras clave: pintura, expresionismo, América Latina, elementos plásticos, análisis formal, paisaje nacional.

\begin{abstract}
Based on the assumption that Latin American artists participated in the international expressionist movement, a formal analysis approach is used to identify plastic elements that characterize this body of artworks in terms of their thematic representation and expressive content. For this purpose a series of recognized works has been considered, where the categorization proposed by Amalia Polleri, Maria Rovira and Brenda Lissardo (1993) is applied, as a necessary first approximation, whose conclusions -far from generating irrevocable deductions- allow to sketch a field of study that can be approached with greater depth in future investigations.
\end{abstract}

Keywords: painting, expressionism, Latin America, plastic elements, formal analysis, national landscape.

\section{Antecedentes}

Si bien no siempre es mencionado por la historiografía del arte, los artistas latinoamericanos participaron en la corriente expresionista a través de distintos diálogos e intercambios, con una intensidad plástica y una vocación vanguardista semejantes a la de los pintores europeos. De esta manera, ellos generaron un cuerpo de obras que comparte el mismo fondo de ideas y modalidades expresivas del movimiento europeo, a pesar de poseer características propias en términos de sus actitudes y valores en torno al proceso de modernización (Frick, 2014 y 2019). Aunque no se ha avanzado en el análisis formal de sus modalidades 
expresivas, alcanza con recorrer la pintura latinoamericana para constatar la existencia de un expresionismo propio, de raigambre local y con semejanzas con el movimiento europeo. Especialmente, en lo que refiere a la distorsión de las formas, la utilización de contrastes y la anulación del espacio tridimensional, con el fin de crear un ambiente y expresar un sentimiento. El objetivo de este breve artículo es generar un aporte crítico al estudio de las dinámicas de propagación, apropiación o influencia del movimiento expresionista, mediante la identificación y análisis de los elementos plásticos que caracterizan a este conjunto de obras en términos de representación del tema y contenido expresivo. Este análisis se construye sobre el entendido de que, si bien el expresionismo no puede limitarse a la supervivencia ocasional de ciertos manierismos, la inexistencia de suficientes antecedentes en la temática a nivel regional, obliga a una primera y muy llana identificación de este tipo de elementos. La propuesta se plantea, de esta manera, como una aproximación necesaria, cuyas referencias y conclusiones permitan bosquejar un campo de estudio que deberá abordarse en el futuro con mayor profundidad.

Consideradas dichas limitaciones, el trabajo se divide en tres partes: En la primera, se definen brevemente las características del movimiento expresionista a partir de la conceptualización realizada por críticos e historiadores del arte latinoamericanos, con la meta de facilitar la generación de un análisis propio capaz de abordar las características del expresionismo regional en diálogo, pero con independencia del movimiento internacional.

Posteriormente, se describen los elementos plásticos de una serie de obras escogidas en tanto ejemplos concretos del desarrollo del movimiento expresionista en la región. Para ello, se utiliza la categorización de los elementos plásticos expresionistas realizada por Amalia Polleri, María Rovira y Brenda Lissardo en su trabajo El lenguaje grafico plástico: Manual para docentes, estudiantes y artistas (1993). Finalmente, se completa el análisis con la lectura del universo simbólico de una serie de obras que abordan la representación del paisaje nacional.

Debe considerarse que la selección de obras se realizó a partir de la identificación y recopilación de los datos dispersos que en las distintas biografías e historias del arte nacional o de los diferentes movimientos artísticos de carácter local que hacen referencia explícita al expresionismo. Como punto de partida esto supone un sesgo en el análisis, ya que las limitaciones en términos del acceso al material obligan a trabajar con una muestra aleatoria de artistas "consagrados", sobre los que existe un mayor número de publicaciones y análisis críticos. Sin embargo, se entiende que es un primer paso en la delimitación de un campo de obras y estudio, que posiblemente requerirá numerosas investigaciones en el futuro.

\section{Una conceptualización propia}

De todos los "ismos" surgidos en el siglo veinte, el expresionismo es uno de los más difíciles de definir. En gran medida, como sugiere María Luz Diez ( 2013) porque es uno de los movimientos más complejos y ricos en lo que supone a sus diferentes manifestaciones, ramas, artistas, miradas y sobre todo su influencia en el arte posterior. El expresionismo es, en este sentido, una "corriente estética amplia y multifacética, subdividida en grupos artísticos afincados en diferentes ciudades” (Vidal, 2007, p. 93) o estado de espíritu susceptible de aplicarse a una gran cantidad de pintores, incluso posteriores a su desaparición (Romero Brest, 1958, p. 56).

Es por esto que, en América Latina, el crítico argentino Julio Payró (1951, p. 117) hizo un esfuerzo por rechazar la dilatación del término y advertir sus diferencias con los demás movimientos modernos que han sido calificados ocasionalmente como expresionistas (como el fovismo, el cubismo, el futurismo y el superrealismo), pero también respecto al "expresionismo subjetivo" (pintura automática no-figurativa), al "expresionismo abstracto" 
(posterior al desarrollo del expresionismo) y al "expresionismo mágico" (que el autor caracteriza como una faceta del superrealismo). Payró se refiere entonces al "expresionismo auténtico" llamándolo "expresionismo objetivo", esto es:

Un arte cuya característica consiste en una deformación de lo real -en forma, en color o en ambas cosas- destinada a hacer resaltar con mucha fuerza aquellos elementos de la realidad que el pintor quiere hacer ver especialmente al espectador. No es otra cosa, en pintura, que la hipérbole de la retórica. Pero, para que un cuadro se clasifique dentro del expresionismo, es indispensable que aquella deformación hiperbólica que no llegue al extremo de alterar las formas tan fundamentalmente como para que éstas dejen de ser reconocibles (Ibídem).

La deformación hiperbólica surge, según Payró, del mismo espíritu que guía el movimiento: un romanticismo desenfrenado que nunca larga la amarra de la objetividad y que jamás es un observador tibio o sereno de lo real. De acuerdo con el autor, animado por un instinto de lucha humanitaria, el artista expresionista "contempla con exaltación apasionada, dominado por el sentimiento: ve lo notable, lo significativo, lo esencial de un espectáculo, y pone todas sus energías al servicio de la descripción insistente de esa esencialidad" (Ibídem).

En este sentido, si bien esta subjetividad es una característica general del arte postimpresionista, los historiadores del arte coinciden en distinguir el espíritu expresionista, en particular, como un estado de "tensión interior" que resulta de un "gran sentimiento cósmico abarcador" (Lafforgue, 1970, p. 28) o del "deseo de totalizar la vida en el estremecimiento de un instante [...] tan complejo y hundido en la subjetividad como para considerarlo símbolo de la expresión misma" (Romero Brest, 1958, p. 48).

Es justamente a partir de esta ansiedad metafísica original que el expresionismo propone un nuevo discurso, en el que el artista reafirma al sujeto y el ideal humanista en la sociedad capitalista moderna, con sus procesos de industrialización, urbanización, racionalización y secularización. Es, de esta manera, un arte político que centra su interés en el contenido como denuncia social, convirtiendo los temas más sencillos "en verdaderas manifestaciones de una crisis de espíritu", reflejo de la necesidad de "una sociedad diferente" de aquella movida por la utopía del progreso (Bassie, 2006, p. 47).

Es por ello que, en general, existe un consenso en la historia del arte respecto al período 1905-1920, como aquél en el que los acontecimientos políticos y el clima social encontraron su expresión artística en el expresionismo. Sin embargo, esto no significa que no puedan encontrar obras expresionistas en la pintura y otras artes con anterioridad o posterioridad a esas fechas. Como tampoco significa que los experimentos de Die Brücke y Der Blaue Reiter sean sus únicas manifestaciones ya que, casi al mismo tiempo que estalla en Alemania el expresionismo se extiende internacionalmente en oleadas que no dejan de sucederse hasta fines de la década del cincuenta (Op. Cit., p. 47).

Tanto es así que de acuerdo a Juan Eduardo Cirlot (1972, p. 379), la mayor parte de la pintura latinoamericana del período anterior a 1945 estuvo matizada de expresionismo. Este "primer expresionismo", además, fue sucedido en la región por el desarrollo del expresionismo abstracto y el neo-expresionismo, que surgieron con la finalización de la Segunda Guerra Mundial y que crecieron en el clima político y social de los setenta (Pini, 2008). Algunos autores han sugerido, además, que el expresionismo se siguió dando en la impronta de las tendencias que se consolidaron en el transcurso del siglo XX, sea cual sea el estilo determinante (Rodríguez et al., 2004).

\section{Elementos plásticos característicos}

Más allá de esta diversidad, en sus orígenes el movimiento expresionista se identifica con los elementos progresistas de principios de siglo, en oposición a las convenciones 
heredadas del siglo diecinueve. El movimiento se caracteriza, de esta manera, por una modalidad particular en el manejo de los elementos plásticos que no se sujeta a lo representado sino a una interpretación subjetiva que se entiende siempre en la dimensión metafísica.

En el arte expresionista existe una validez absoluta de la visión personal, que se representa mediante colores y formas que se arremolinan juntos en una especie de tormenta pictórica cuyo impacto visual, extremadamente emotivo, nada tiene que ver con el tema central, sino que es producto del medio, que tiene una vida y un movimiento propio (Denvir, 1975, p. 31). En términos generales, esto supone el claro abandono del "motivo artístico" y de los valores pictóricos y compositivos tradicionales de la pintura, y la búsqueda de la potencialidad expresiva de los objetos sobre las formas, el sensualismo y los tonos atractivos. Como describe Jorge Romero Brest:

Cuando un aficionado a la pintura se encuentra con un [...] cuadro romántico expresionista, se le impone con pasmosa rapidez el deseo del artista de que abandone el mundo de las relaciones concretas, siente que todo está referido a una instancia de valor ajena al hombre de carne y hueso y percibe que son imágenes de cosas irreales [...] Ésta es la actitud que ha de tenerse cuando se trata de comprender la obra de los expresionistas, en las que todo es sugestión y misterio, impulso. [...] la virtud de ellos ha sido la de desgajar la sugestión, el misterio y el impulso de las formas representativas, transformándolos en estados de tensión que se manifiestan de manera abstracta en la línea y el color, o en los ritmos igualmente abstractos de la composición (1958, p. 93).

Desde el punto de vista del análisis formal, tal tensión y misterio expresionista se caracterizan por una modalidad particular en el manejo de los elementos plásticos que pocas veces se han categorizado de manera sistemática. En este sentido, resulta especialmente relevante la propuesta realizada por las uruguayas Amalia Polleri, María Rovira y Brenda Lissardi (Polleri et al., 1993) que -aunque sucinta- permite avanzar en la identificación de sus principales elementos y modalidades expresivas.

De acuerdo con estas autoras, los elementos plásticos expresionistas pueden resumirse en los siguientes: (1) trazado acentuado (utilización de líneas fuertes y firmes); (2) proporciones anormales (no aplicación del canon o la perspectiva), y (3) formas monumentales; (4) color modulado (sustitución del claroscuro por cálidos y fríos en la creación de volumen); (5) trasposición del color (por ejemplo, rostros verdes y caballos azules); (6) afirmación de ritmos expresivos (impulso direccional a partir de la repetición, sucesión, interrupción o variedad de líneas, formas o color); y (7) tratamiento vigoroso de la pincelada y texturas empastadas.

En su conjunto, estos elementos aparecen en obras como Paisaje Bunti de Xul Solar (1916), La boba de Anita Malfatti(1916), Cristo destruye su cruz de José Clemente Orozco(1922), Las beatas de Julia Codesido (1932), Virgen del Cobre de Carlos Enríquez (1933), Cama 33 T.B. Evacuable de Cecilio Guzmán de Rojas (1934), Navío de emigrantes de Lasar Segall (1939), La guerra de Ricardo Grau (1943), Mantas de Julia Codesido (1945), Florida de José Cuneo Perinetti (1942), El diablo en la iglesia de David Alfaro Siqueiros (1947), Procesión de Eduardo Kingman (1948), Paisaje rosado con río de José Sabogal (1954), Gallero de César Andrade Faini (1956), Gaucho herido de Miguel Angel Pareja (1950), Anunciación de Carlos Alberto Castellanos (1930) (Fig.1.). En términos generales, este conjunto de obras puede catalogarse como claramente representativo de una tendencia expresionista local, en el sentido de que no dejan lugar a dudas respecto a la actitud o espíritu de su creador.

Pero en muchos otros casos, el protagonismo de los elementos plásticos expresionistas tiene un carácter más sutil o el espíritu expresionista de las obras se canaliza a través de uno sólo de ellos, en el que apoya toda la fuerza de su expresión. No obstante, considerando la 


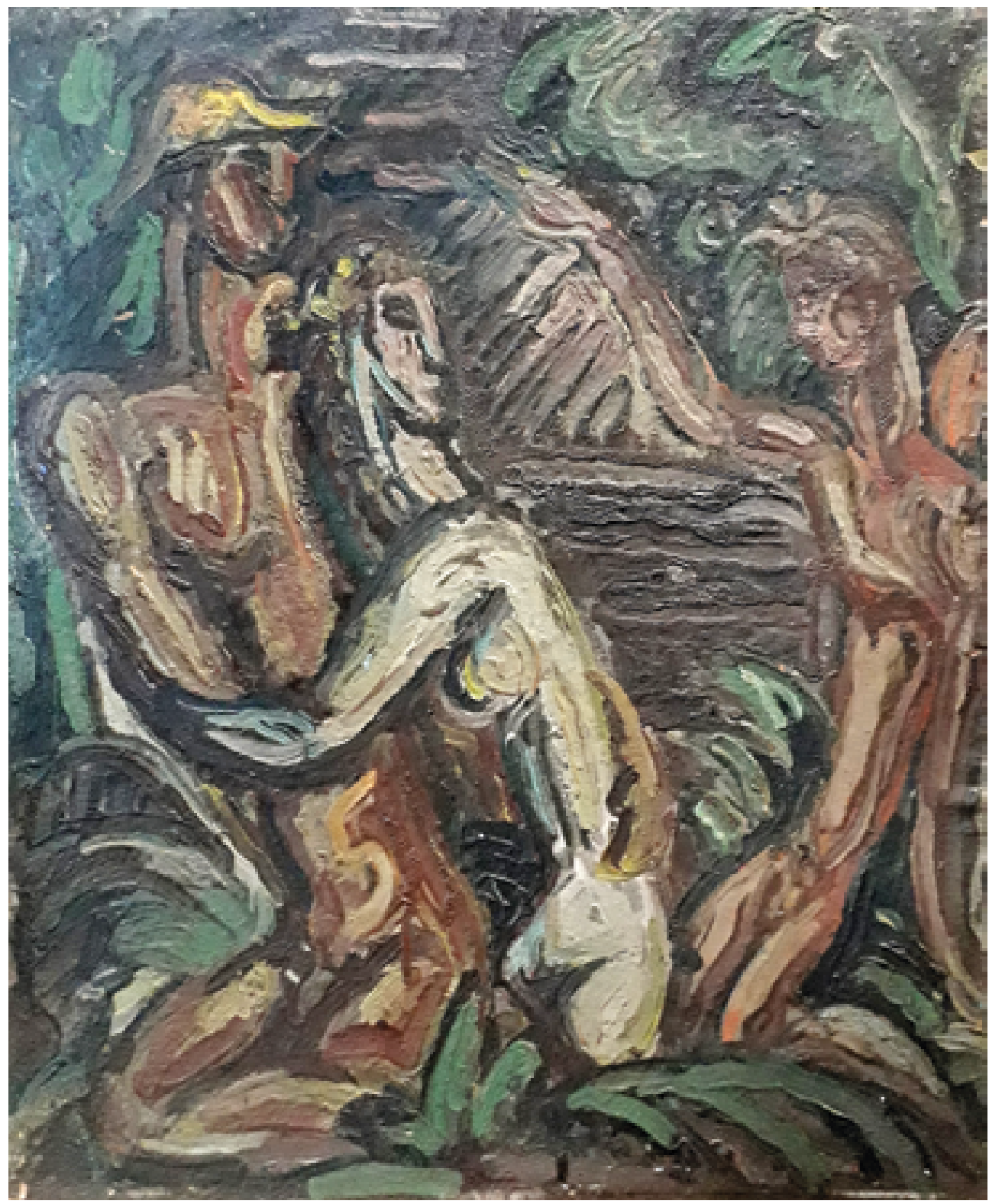

Fig. 1. Carlos Alberto Castellanos. Anunciación. Ca.1930. Óleo sobre cartón, 64 x 54 cm. Museo Nacional de Artes Visuales (MNAV), Montevideo.

complejidad de manifestaciones, ramas y miradas expresionistas, a partir de los elementos propuestos por Polleri, Rovira y Lissardi (1993) es posible reconstruir las similitudes que muchas de estas obras presentan con otras del movimiento europeo.

De esta manera, en primer lugar, es posible constatar la marcada presencia de trazados acentuados. Al igual que en el trabajo de Egon Schiele u obras como Joven pareja de Emil Nolde o Casas cerca de Gravel Pit de Paul Klee, la utilización de líneas fuertes y firmes como 
elemento plástico dominante se manifiesta en obras como Mercado de Girardot de Guillermo Wiedemann (1950)y Temor de Olga Blinder (1966). Y es igualmente evidente en La Virgen del Cobre de Carlos Enríquez (1933), Autorretratode José Orozco (1949), El espíritu del tango de Carlos Torrallardona (1978), Amantes II de David Herskovitz (1987) o Bosque otoñal de Arturo Barcia (1999), entre tantas otras. En todas ella, el trazo conduce la mirada del espectador sugiriendo una voluntad de orden que expresa lo que Jorge Romero Brest (1958, p. 52) llamó la "fuerza organicista indomable característica del movimiento expresionista".

En segundo lugar, así como la utilización de proporciones anormales mediante la no aplicación de la perspectiva o la distorsión de la forma aparece claramente en Schiele, Permeke, Kirchner, Pechtein o Munch, en la pintura latinoamericana es característica de las obras de Oswaldo Guayasamín y Eduardo Kingman. La monumentalidad de la forma también es característica de obras como El cerdo y su amante de Leopoldo Presas (1960). Los Andes de Sérvulo Gutiérrez (1943), Memorias de Grünewald de Ernesto Deira (1967), La cosecha de Ximena Cristi (1976) o Cortés y la Malinche de José Clemente Orozco (1926).

Como explica Lotte Eisner (1955, p. 16) en referencia a la utilización de proporciones anormales, se trata de una "deformación seleccionada y creadora" que busca restituir la vida interna de los objetos y "expresar su alma”. Esto es claro, por ejemplo, en Sábanas rojas de David Herskovitz (1982), que incorpora figuras monumentales que, además de ser centrales, tienen un alto nivel de erotismo. Tal como describe Raúl Castro:

El erotismo en esta obra es sorprendente, por ser, a la vez, carnal y visionario. Si en otros cuadros el color rojo genera un clima feroz y despiadado, en esta obra es un fuego de vida y felicidad alborozada. En vivo desenfreno, la pareja de amantes -que son dos colosos- parecen fusionarse ante la mirada del observador en una situación que reboza deseo irrefrenable y proyecta, sin embargo, una vigorosa impronta trascendente. Podría hablarse de un misticismo del goce corporal nunca antes visto en la pintura nacional $(2010$, p. 81$)$.

En esta misma línea, la centralidad del color mediante el uso de contrastes, tonalidades y modulaciones es evidente en las obras de Emil Nolde o Ernst Ludwig Kirchner, es igualmente importante en El hombre amarillo de Anita Malfatti (1915-6), Paisaje industrial de Gabriel Fernández Ledesma (1929) o El ciego de Ricardo Aguerre (1934), así como en las obras de Carlos Enríquez, José Sabogal, Sérvulo Gutiérrez, Víctor Humareda y más recientemente, en la producción de Augusto Barcia, Enrique Polanco, Rómulo Macció, Ernesto Deira y Alejandro Obregón. Al respecto, críticos como Romero Brest (1958) han dicho que los expresionistas demuestran una relativa incapacidad para otorgar expresión al color en sus dimensiones tonales, por lo que cuando se lo emplea en tintas planas, es el dibujo el que vuelve a predominar. Se ha sugerido, incluso, que su manejo de las normas convencionales de la perspectiva resultaba simplemente de la ignorancia de los artistas, que en muchos casos eran autodidactas sin formación académica (Rhodes, 2005).

Sin embargo, hay también quienes defienden la idea de una intencionalidad consciente cuyo objetivo es representar la complejidad psíquica con intensidad. Tal es el caso, entre otros, del venezolano Jacobo Borges, cuyos colores alcanzan la misma violencia que en la pintura de George Grosz y en cuya obra observa la influencia de la tradición expresionista que va de James Ensor hasta Willem de Kooning. Como describe Aura Guerrero:

El estilo deviene en un fuerte expresionismo y gestualismo que le permite denunciar y confrontar los abusos de quienes detentan el poder [...] Sus obras se pueblan de muchos personajes [...] todos son grotescos, producen repulsión [...] También hay una violencia del color: Borges generalmente usa el negro, el gris, el naranja y sobretodo el rojo, con el cual construye el espacio, según lo use de fondo o en determinadas zonas de la obra [...] 
El rojo se convierte en una constante [...] se considera agresivo, vital, cargado de energía, afín al fuego y sugiere tanto el amor como la lucha entre la vida y la muerte (Guerrero, 2008, párr. 54).

En cuarto lugar, la afirmación de ritmos expresivos a partir de la repetición, sucesión, interrupción o variedad de líneas, formas o color que es característica de pintores europeos como Kandinsky y Marc, en América Latina se hace patente en obras como las selvas de Macedonio de la Torre o en los ritmos expresivos de Gíldaro Antezana. Tal como describe el crítico boliviano Harold Suárez:

Técnicamente, su pintura era resuelta con una adecuada distribución de los elementos en el espacio determinado, puntos de fugas, perspectivas lineales y manejo magistral y simétrico de la composición áurea [...] Todos los elementos plásticos composicionales, incluso los más inertes se transforman adquiriendo una renovada y llamativa identidad quedando, sin referencias temporales, más próximos a una realidad sensible, que a una objetual. Nos muestra la impactante fuerza expresiva de una sensibilidad que le permite encontrar emocionantes relatos aún en los más insignificantes objetos de su entorno (Suárez, 2010, s. p).

Finalmente, el tratamiento vigoroso de la pincelada y las texturas empastadas son también particularmente relevantes en el expresionismo en la región. Al igual que la obra Cabeza de mujer con girasoles de Ernst Ludwig Kirchner, en la que la dirección de las pinceladas es el único elemento que da sustancia a las formas, obras como Autorretratode José Clemente Orozco (1940), son características de esta tendencia. Como describe Leopoldo Castedo (1979), en la pintura de Orozco los trazos coinciden con los de Van Gogh, "incluida la presunción de locura, son enérgicos, como flechas, y nada modestos”.

Otro ejemplo es Paisaje con Huarangos de Sérvulo Gutiérrez (1953), en que se observa el empleo de raspones con los dedos o algún material que lo permita, con movimientos del pincel como gestos de una intensa expresividad, que llega a convertirse en un motivo más importante que el tema. Como describe Víctor Acosta:

Podemos apreciar [...] cómo el artista en movimientos magistrales del pincel plasma el efecto del viento, haciendo al árbol del Huarango parecer como un cuerpo que esta incendiado y agitado por los movimientos ondulantes del aire que involucra a todo paisaje. Sérvulo como un buen observador al pintar esa atmósfera le da un carácter de extraña tranquilidad a la obra. Está pintada en su mayoría con tonalidades violetas, verdes, amarillos y el blanco de la arena, realizando en conjunto un juego de contrastes de luces y sombras. El paisaje está en un movimiento por el constante viento con un árbol de Huarango que se está en combustión (Acosta, 2008, p. 221).

\section{Señas de un expresionismo auténtico}

Cuando el análisis de estos recursos plásticos se complementa con la lectura del universo simbólico de las obras, es posible constatar de manera más evidente todavía la existencia de un cuerpo de pintores y obras latinoamericanas de tendencia expresionista. Esto es notorio, entre otros ejemplos posibles, en las obras que abordan el paisaje y la naturaleza, no como una forma de resistencia a la cultura burguesa -como sucedía en el caso europeo- sino como respuesta a la necesidad de representar el mundo todavía inexplorado del paisaje nacional.

Un caso claro, en este sentido, es la obra Florida de José Cuneo Perinetti (1942), que ejemplifica la adaptación del lenguaje plástico expresionista en la representación de la soledad de las ondulaciones el paisaje local. Cuneo, pintó una serie de motivos con ranchos que se caracterizan por la deformación de los objetos y los planos inclinados, en las que lunas 


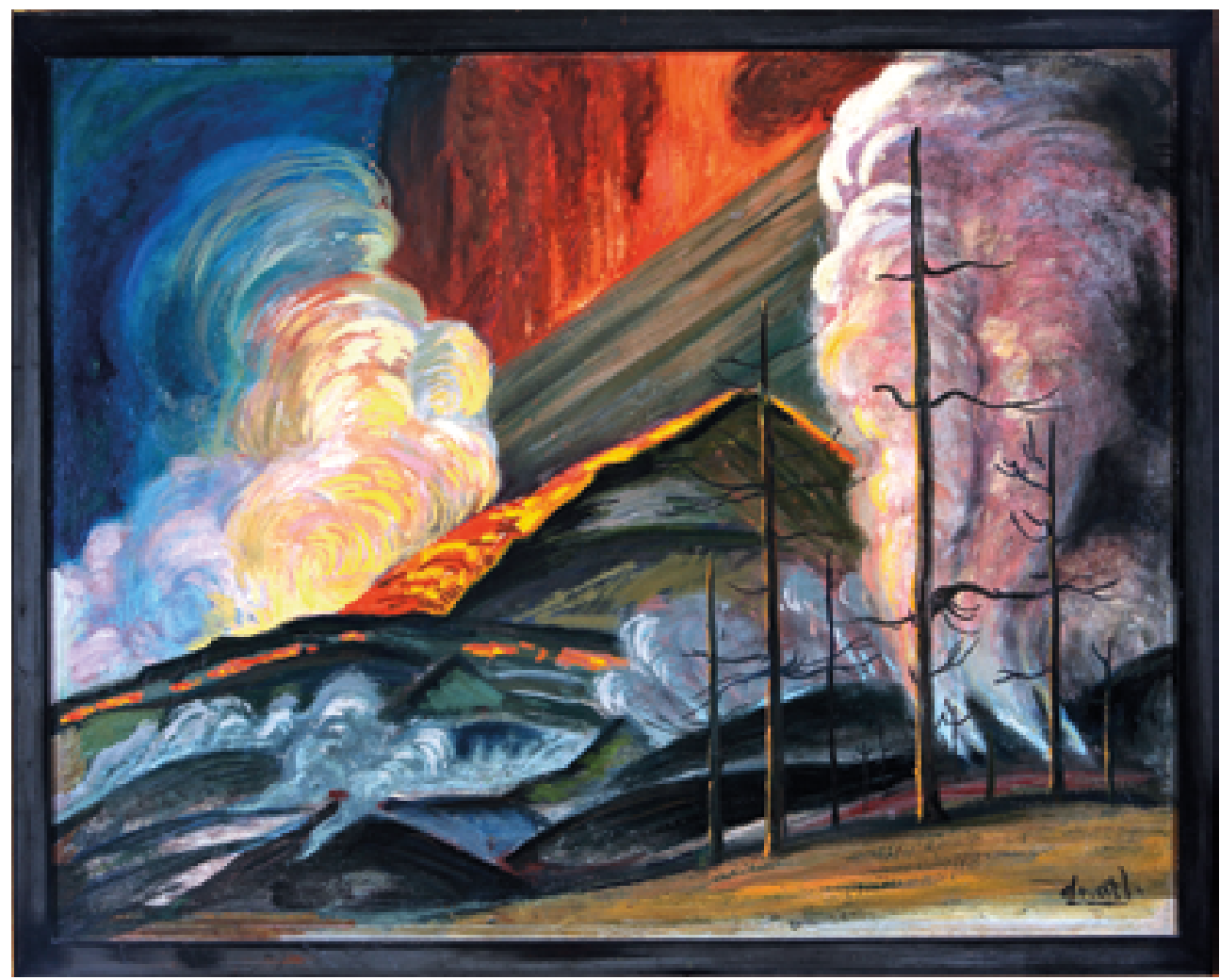

Fig. 2. Dr. Atl (Gerardo Murillo). Paricutín. Ca. 1943. Colores de Atl y óleo sobre cartón, 72 x $93 \mathrm{~cm}$. Colección Andrés Blaisten, México.

inmensas irradian luz en poderosos halos o las formas repetidas de las nubes ocupan todo el cielo (Da Cruz, 2009). Su obra Florida (1942), en particular, representa "un mundo de inquietudes y temores" que se hace evidente en la "miserable vivienda del paisano criollo que emerge del terreno como un accidente de la misma tierra". Tal como describe Alicia Haber:

Los terrenos se hunden bajo la presión del dinamismo cósmico, los ranchos se inclinan en peligroso equilibrio, las nubes y el halo lunar adquieren un potencial expresivo, hay ominosas presencias de pájaros negros. Es un mundo donde todo se agita y metamorfosea y el cielo majestuoso se impone sobre seres y cosas. Ese dinamismo cósmico está expresado plásticamente por el abandono de las horizontales y verticales, el predominio de la composición diagonal, las grandes áreas de contrastes de luz y sombra, y los profundos ritmos que generan las formas de nubes y árboles. La oblicuidad otorga un carácter dinámico a la composición y todo parece agitarse, adquiriendo las formas contornos móviles. La tensión visual es muy potente y el pintor logra infundir vida a lo inerte: ranchos, nubes, osamentas, postes y vegetación adquieren una fuerte capacidad de transmisión de sentimientos (...) La deformación de las estructuras aumenta esa sensación, y ésta se refleja también en los movimientos de las pinceladas: la factura contiene un importante caudal expresivo (Haber, s.f.: párr. 2).

Ejemplos similares son las obras José Clemente Orozco sobre el maguey. De acuerdo a Teresa del Conde (1994, p.24), en Paisaje mexicano (1932) Orozco plasma un mensaje sutil, 
pero de fuerte crítica social, utilizando como figura principal un enorme maguey, que aparece como símbolo del paisaje y de la identidad nacional. Como describe Teresa Conde:

En este "Paisaje mexicano" se encuentran cuatro personajes, paradójicamente el central es un enorme maguey mutilado que parece representar nuestra nacionalidad, a la que le ha extraído el líquido vital; en este caso el aguamiel, pero pese a estas condiciones aún continua firme y con enorme fortaleza en cada uno de sus tallos (...) Una fría y sombría atmósfera rodea el paisaje (...) las nubes forman figuras duras y caprichosas, junto a un cielo presagiante de una tormenta (...) Los colores de la composición contrastan entre sí (...) Toda la composición en su aparente sencillez y con los escasos elementos ahí representados es rica en una propuesta de denuncia por demás contundente que caracterizó la obra de este artista excepcional. (Conde, 1994, p. 24).

En esta misma línea se encuentran también: Arquitectura geográfica (1959), Cactus en el desierto, Volcán en erupción (1964) y Una montaña de oro de David Alfaro Siqueiros (1964), además de los magníficos volcanes de Gerardo Murillo (Dr. Atl) (Fig.2), la serie sobre las monumentales ruinas incaicas realizada por Cecilio Guzmán de Rojas, los paisajes angolinos de Israel Roa, las selvas de Macedonio de la Torre, o los paisajes chilenos de Ximena Cristi y Augusto Barcia. Pero el interés expresionista por el paisaje también supone la representación del mundo animal, especialmente como forma de señalar una geografía y una fauna con pleno carácter local. Éste es el caso, por ejemplo, de los animales que pintó Oscar Corcuera, de los caballos de Víctor Humareda, de los gallos de pelea de Gíldaro Antezana, o de los cóndores de Alejandro Obregón. Pero también pinturas como Toro, sol y vicuña de José Sabogal (1948), una obra de clara tendencia expresionista:

En la segunda mitad de la década de 1940 (...) Sabogal retomó un motivo que había aparecido antes en su pintura: la alegoría. Animales autóctonos representados por el cóndor en vuelo y la vicuña, se encuentran con aquellos que llegaron tras la Conquista, presentes en las figuras del toro y el caballo. Esta conjunción simboliza el inicio de un nuevo mundo que, producto de dos culturas distintas, está compuesto por oposiciones: pasiones y quietudes, violencias y repliegues. Al parecer, una composición propia de una segunda mirada de Sabogal hacia el mundo andino (Castro, 2010b, p. 79).

En este sentido, así como a partir del análisis formal de una selección de obras es posible inducir que muchos pintores latinoamericanos se sirvieron de los elementos y principios expresionistas en el desarrollo de sus obras, en términos de las opciones temáticas se puede confirmar que en muchos casos ellos también se apropiaron de las ideas y principios plásticos del expresionismo europeo de acuerdo a sus intenciones y necesidades de expresión y representación de su propia realidad. Es decir, que adaptaron los principios generales del expresionismo en la creación de un arte nuevo y singular que representaba sus propios deseos y utopías dadas de las condiciones objetivas de su lugar de producción.

\section{Comentarios finales}

Si bien el análisis formal es recién un primer paso, acotado y específico, en la identificación de la pintura expresionista en la región, permite identificar claramente y de manera sistemática los elementos plásticos que caracterizan a estas obras en términos de la representación de los temas y su contenido expresivo. En este sentido, a partir de las categorías propuestas por Polleri, Rovira y Lizardi (1993), así como el repertorio temático desarrollado por Bassie (2006), es posible constatar la supervivencia de ciertos elementos y características de representación que definen a un cuerpo de obras de tendencia expresionista. 
Lejos de generar deducciones irrevocables, esta constatación abre un campo de estudio que deberá abordarse en el futuro con mayor profundidad, incorporando herramientas del análisis estilístico, iconográfico y sociológico.

A pesar de ser modesto en su propuesta, este artículo sienta las bases para futuras investigaciones. En este sentido, respecto al contenido simbólico de las obras, en particular, sería fundamental identificar cuál es la "neurosis", la "ansiedad metafísica", el "ideal humanista" o la preocupación central que manifiesta el expresionismo latinoamericano y en qué medida se posiciona como un "arte político" en relación con los movimientos políticos y sociales de la región. Del mismo modo, sería interesante identificar con detalle las distintas manifestaciones y ramificaciones que adopta en la región en referencia a movimientos como el fovismo, el futurismo, el cubismo, el indigenismo, el muralismo, el realismo mágico, el informalismo, el realismo naturalista, la nueva objetividad, el expresionismo abstracto, el neoexpresionismo, además de otras agrupaciones locales.

\section{Referencias bibliográficas}

Acosta, V. "Los huarangos de Sérvulo Gutiérrez". En Zonas Áridas, №12, Vol. 1, pp. 218-224. Recuperado de: http:/www.lamolina.edu.pe/zonasaridas/za12/pdf/PINTORZA12.pdf, 2008.

Bassie, A. Expresionismo. México: Editorial Neumen, 2006.

Castedo, L. "Orozco: compromiso y angustia de México". En El País (España). Recuperado de: http://elpais.com/diario/1979/06/21/cultura/298764009_850215.html, 21 de junio de 1979.

Castro, R. (Ed). Maestros de la pintura peruana: David Herskovitz. Lima: Empresa Editora El Comercio, 2010.

Castro, R. (Ed). Maestros de la pintura peruana: José Sabogal. Lima: Empresa Editora El Comercio, 2010b.

Cirlot J. Pintura. Vol. 2. Barcelona: Editorial Labor, 1972.

Conde, T. "Pintura de caballete y dibujo: principales muestras del siglo XX en el extranjero". En Rodríquez, I. (Ed.), México en el mundo de las colecciones de arte: México Contemporáneo, I . México: Fondo de Cultura Económica, 1994.
Da Cruz, P. "José Cuneo entre las lunas, ranchos y abstracciones". En El País (Uruguay). Recuperado de: http:/historico.elpais.com.uy/091016/ pespec-448279/espectaculos/jose-cuneo-entrelas-lunas-ranchos-y-abstracciones/, 16 de octubre de 2019.

Denvir, B. El fauvismo y el expresionismo. Barcelona: Editorial Labor, 1975.

Diez, M.L. "Expresionismo. Entre la protesta y la evasión”. En Crac Magazine, № 8, Año 2, pp. 7-14, 2013.

Eisner, Lotte. La pantalla diabólica. Panorama del cine alemán II: Influencia de Max Reinhardt y del expresionismo. Buenos Aires: Ediciones Losange, 1955.

Frick, M. "El expresionismo en la pintura latinoamericana: transferencias y trascendencia" En Atrio, $\mathrm{N}^{\circ} 20,2014$.

Frick, M. "Expressionism in Latin America and Its Contribution to the Modernist Discourse". En Isabel Wünsche (Ed.), The Routledge Companion to Expressionism in a Transnational Context. New York: Routledge, Taylor \& Francis Group, 2019. 
Guerrero, A. "A través de la ventana. Del paisaje y otros temas en la pintura venezolana (1850-1970)". En Revista Argos, $\mathrm{N}^{\circ}$ 49, Vol. 25, pp. 45-72. Recuperado de: http://ve.scielo. org/scielo.php?script $=$ sci arttext $\&$ pid $=$ S0254-16372008000200004, 2008.

Haber, A. Museo Virtual de Artes de El País: Florida 1942. Recuperado de: http://muva.elpais.com.uy/ Esp/planta_baja/sala8/info/index11.html, s.f.

Hauser, A. Historia social de la literatura y el arte III: naturalismo e impresionismo bajo el signo del cine. Madrid: Editorial Guadarrama, 1969.

Hoffmann, W. Los fundamentos del arte moderno. Barcelona: Ediciones Península, 1992.

Lafforgue, J. El expresionismo teatral. Buenos Aires: Centro Editor de América Latina, 1970.

Payró, J. Héroes del color: vida, obra, teorías y gravitación de los maestros postimpresionistas fundadores del arte contemporáneo. Buenos Aires: Editorial El Ateneo, 1951.

Pini, I. "Arte latinoamericano desde 1930 hasta la actualidad". En Palacio, M. (Ed.), Historia general de América Latina VIII: América Latina desde 1930. París: Ediciones Unesco, Editorial Trotta, 2008.

Polleri, A., Rovira, M. y Lizardi, B. El lenguaje grafico plástico: Manual para docentes, estudiantes y artistas. Montevideo: Ediciones Banda Oriental, 1993.

Rhodes, C. "Vicios y virtudes del imperativo autodidacta". En Soikam A. (Ed.), Expresionismo Brücke. Actas del Museo Thyssen-Bornemisza, $\mathrm{N}^{\circ} 4$, pp. 51-72. Recuperado de: https://studylib.es/ doc/7259164/actasdelmuseothyssen---bornemisza---n-\%C2\%BA-4, 2005.

Rodríguez, M. "La constante expresionista en la pintura chilena”. En Guzmán, F., Cortéz, G. y Martínez, J.M. (Ed.), Arte y crisis en Iberoamérica: Jornadas de Historia del Arte en Chile. Santiago de Chile: RIL Editores, 2004.
Rodríguez, M.A. (2018). "Aníbal Villacís, celebración". En diario El Comercio, sección Opinión, martes 20 de febrero 2018.

Román, E. "Encuentro con Tola”. En Catálogo de exposición "JOSÉ TOLA: Dios, la muerte, el tiempo y yo", Arequipa: Centro Cultural de Arequipa, 13 de abril al 27 de mayo, pp. 4-9, 2011.

Romero Brest, J. La pintura europea contemporánea (1900-1950). México, D.F.: Fondo de Cultura Económica, 1958.

Schwartz, J. "Modernismo revisitado: la Caja modernista". En Revista Casa del Tiempo, № 83-84, pp. 35-42. Recuperado de: http://www.uam.mx/ difusion/casadeltiempo/83_dic_ene_2005/casa_ del_tiempo_num83_35_42.pdf̄, $200 \overline{5}$.

Suárez, H. "Entre gallos, girasoles y Caytanos". En Suplemento Cultural "La Ramona" del Diario Opinión, Bolivia, 27 de junio del 2010. Recuperado de: https://www.elcomercio.com/app_public. php/opinion/opinion-columnistas-marcoantoniorodriguez-anibalvillacis-celebracion.html, 2010.

Vergo, P. "Brücke: ¿un puente hacia el "superhombre"?". En Soika, A. (Ed.), Expresionismo Brücke. Actas del Museo Thyssen-Bornemisza, $\mathrm{N}^{\circ} 4$, pp. 19-36. Recuperado de: https://studylib.es/ doc/7259164/actasdelmuseothyssen---bornemisza---n- $\%$ C2\%BA-4.

Vidal, N. "Arte y técnica. Estética. Lenguaje. Tecnología. Fascismo. Un capítulo pendiente sobre la condena al expresionismo alemán”. En Revista Artefacto [en línea], № 6, 2007.

Recibido el 15 de septiembre del 2019 Aceptado el 25 de septiembre del 2019 